\title{
Indagando a "História única" no ensino de frações por meio do olho de Hórus, um Deus do Kemet
}

\author{
Getúlio Rocha Silva1 ${ }^{1}$ \\ ABPN/IFBA \\ Luiz Marcio Santos Farias 2 \\ Univeversidade Federal da Bahia \\ Dossiê | Dossier | Dosier \\ DOI do artigo: 10.22481/odeere.v6i2.9877
}

\begin{abstract}
RESUMO
Este texto contribui para a desconstruir falácias racistas que forjaram discursos deletérios aos povos não europeus. O conceito de "História única", apresentado pela escritora Chimamanda Adichie e a canção Faraó - Divindade do Egito, do compositor Luciano Gomes, foram incitadores do artigo. Apontamos posicionamentos de filósofos que contribuíram para arquitetar o racismo científico e os relacionamos às narrativas que defendem a unicidade da Matemática. A fábula da Matemática única é uma forma de negar as técnicas matemáticas elaboradas por grupos étnicos que não ocupam posições de poder na Academia. Objetivamos, por meio da decolonialidade e da interdisciplinaridade crítica (Walsh, 2009), subsidiar proposições de ensino em classes de Educação de Jovens e Adultos que atendam as Diretrizes Curriculares Nacionais para Ensino das Relações Étnico-Raciais. Africanos antigos foram os inventores do objeto matemático fração, bem como da sua notação atual. Os mais antigos registros históricos sobre esse objeto são os papiros keméticos, sendo o papiro de Ahmes o mais importante deles. Este documento histórico apresenta diversas contribuições africanas para a Matemática. Por fim, recorremos ao Mito Hórus, um deus kemético, para ressaltar que frações estavam relacionadas ao cotidiano da civilização egípcia antiga.
\end{abstract}

Palavras-chave: Ensino de Matemática. Decolonialidade. Interculturalidade crítica. Fração.

\section{Inquiring the "Unique story" in the teaching of fractions through the eye of Horus, a God of Kemet}

\begin{abstract}
This text contributes to deconstruct racist fallacies that forged harmful speeches to non-European peoples. The concept of "Unique History", presented by the writer Chimamanda Adichie and the song Faraó - Divindade do Egito, by composer Luciano Gomes, were inciting the article. We point out the positions of philosophers who contributed to building scientific racism and relate them to narratives that defend the uniqueness of Mathematics. The fable of unique Mathematics is a way of denying the mathematical techniques developed by ethnic groups that do not occupy positions of power in the Academy. We aim, through decoloniality and critical interdisciplinarity (Walsh, 2009), to support teaching propositions in Youth and Adult Education classes that meet the National Curriculum Guidelines for Teaching Ethnic-Racial Relations. Ancient Africans were the inventors of the mathematical object fraction as well as its current notation. The oldest historical records about this object are the kemetic papyrus, the Ahmes papyrus being the most important of them. This historical document presents several African contributions to mathematics. Finally, we turn to the Myth Horus, a kemetic god, to emphasize that fractions were related to the daily life of ancient Egyptian civilization.
\end{abstract}

Keywords: Mathematics Teaching. Decoloniality. Critical interculturality. Fraction.

Submetido em: 10/11/2021| Aceito em: 14/12/2021

1 Professor no IFBA. Mestre em Cultura e Sociedade (UFBA). Licenciado em Matemática (UESB). Email: getulio.silva@ifba.edu.br

2 Professor do Instituto de Humanidades, Artes e Ciências Prof. Milton Santos (IHAC), Coordenador do Bacharelado Interdisciplinar em Ciência e Tecnologia-IHAC, da Universidade Federal da BahiaUFBA, da Faculdade de Educação da UFBA e do Programa de Pós-Graduação em Ensino, Filosofia e História das Ciências da UFBA/UEFS, do qual foi coordenador de 2014 a 2016 e de 2016 a 2018. Graduado em Matemática (UFBA/UCSAL), Pós-graduado em Didática e Metodologia do Ensino Superior (EEAB), Mestre (UJF-França) e Doutor (UM2-França) em Didática das Ciências e Matemática. E-mail: Imsfarias@ufba.br 
"Osíris proclamou matrimônio com Ísis

E o mal Seth, irado o assassinou"

$[\ldots]$

"Hórus levando avante a vingança do pai

Derrotando o império do mal Seth

O grito da vitória que nos satisfaz"

$[\ldots]$

"E as cabeças

Se enchem de liberdade

O povo negro pede igualdade"

Luciano Gomes

\section{Matemática única?}

Os excertos acima são trechos da música Faraó - Divindade do Egito, composta por Luciano Gomes. A canção é considerada um dos hinos do carnaval baiano e trata de aspectos mitológicos do antigo Egito (Kemet). Um sucesso inquestionável que ecoa nas vozes de diversos artistas e anônimos, há mais de 3 décadas. Nesse texto, a música é motivadora de reflexões para o ensino de frações. Faraó - Divindade do Egito, se refere a deuses egípcios e também aos anseios por liberdade e justiça. A canção nos encaminha à antiguidade Kemética e às riquezas culturais dos povos que, atualmente, são denominados africanos.

Africanos antigos e afrodiaspóricos inventaram diversas tecnologias e contribuíram muito para a humanidade, inclusive para a Matemática. Entretanto, o ensino escolar, embasado em uma forma única de Matemática, silencia ou ignora tais contribuições. "A história única" (ADICHIE, 2019), de acordo com esta autora, é um perigo que provoca diversas consequências, dentre elas: (1) avaliações de culturas diferentes por um viés singular e particular; (2) desconhecimento das potencialidades e das diversidades culturais e dos modos de fazer peculiares; (3) as narrativas propaladas sobre grupos socioculturais marginalizados passam a defini-los; e (4) personalidades são moldadas por meio das hierarquizações. Chimamanda Adiche ressalta que a história única "rouba a dignidade das pessoas", sendo impossível expressá-la, sem falar de poder. "O poder é a habilidade não apenas de contar a história de outra pessoa, mas de fazer que ela seja sua história definitiva" (ADICHIE, 2019). A história se torna, desse 
modo, performativa. Como categoria da linguagem, a performatividade, admitindo a identidade como movimento, desloca a ênfase da descrição para a construção (SILVA, 2009). Ou seja, as diversas formas de repetir uma "história única" constroem, reiteradamente, subalternidades e hierarquizações. Uma das decorrências disto é que indivíduos são diuturnamente violentados na sociedade e no ambiente escolar ao não se verem representados dentro dos grupos de pessoas que governam, que inventaram fórmulas, que descobriram propriedades físico-químicas, ou que inventaram coisas que melhoraram a vida humana, etc. Versões da "história única" são reiteradas em vários lugares e ambientes: nos programas de televisão, na escola, nas ruas, nos lares, nos grupos religiosos, dentre outros, e seguem moldando identidades.

A perspectiva única da Matemática, imposta pelo currículo, é uma das facetas da "história única". Esta, além de silenciar estratégias matemáticas de culturas não europeias, impede os estudantes de compreenderem outras formas de matemáticas. Paulo Freire propôs aos professores desta área trabalharem contra o elitismo (MENDONÇA, 1995). Para atender a proposição freireana é necessário questionar a epistemologia hegemônica do ensino de Matemática. Isso não significa, de modo algum, desprezar ou desvalorizar a Matemática escolar e sim colocar em jogo (GIRALDO, MATOS e QUINTANEIRO, 2020) diversas epistemologias matemáticas que foram ignoradas.

Este texto tem o propósito de subsidiar o atendimento das Diretrizes Curriculares Nacionais para o Ensino das Relações Étnico-Raciais - DCNERER (BRASIL, 2006) em aulas de Matemática que tratem do estudo de frações. Este objeto matemático já fazia parte da cultura do Kemet (Terra Negra), nome do antigo Egito (PINHEIRO, 2021) e aparece em papiros matemáticos daquele período.

O artigo 26-A da Lei de Diretrizes e Bases da Educação Nacional, determina que História e Cultura Afro-Brasileiras e Indígenas sejam abordadas no ensino em todo o currículo escolar. O inciso XII, do artigo 3o da mesma lei, indica que considerar a diversidade étnico-racial é um dos princípios do ensino (BRASIL, 1996). O objeto matemático, em questão, pode ser desenvolvido de forma interdisciplinar e também atender as DCNERER. Acreditamos que este artigo pode colaborar para isso, de forma interdisciplinar porque tratar de um mito egípcio pode envolver os 
componentes curriculares História, Arte, Religião, Geografia, Filosofia, Sociologia, Direito, dentre outros. Como a mitologia informa sobre assassinato, batalhas, acreditamos que o texto seja mais recomendado para ações interdisciplinares na Educação de Jovens e Adultos - EJA, por se tratarem de estudantes com maior faixa etária.

Rosiléia Santana da Silva e Luiz Marcio Santos Farias (2020) identificaram professoras e professores da Educação Básica que se interessavam em implementar o Ensino e História da Cultura Afro-Brasileira nas escolas, mas, não conseguiram por falta de referenciais metodológicos ou teóricos (R. SILVA e FARIAS, 2020). De acordo com os autores, a privação de referenciais para o ensino envolve tanto materiais, quanto propostas didáticas. Outro autor, Gustavo Forde, nos informa que durante a Graduação, os professores de Matemática não têm acesso às contribuições africanas para a Matemática e que os livros didáticos, do mesmo modo, não apresentam essas contribuições (FORDE, 2017). Em virtude disso, perseveramos com o que propusemos em texto anterior, "construir uma noosfera que favoreça pesquisas e divulgações das contribuições africanas para a Matemática" (SILVA e FARIAS, 2020). Isto se faz necessário porque é preciso valorizar as elaborações africanas para a Matemática, construindo, desse modo, histórias que se contraponham àquela que desvaloriza nossas identidades e as histórias de nossos ancestrais.

A BNCC indica o início do trabalho com frações no 4 o ano do Ensino Fundamental. Durante esta etapa da Educação Básica é esperado que os estudantes compreendam frações, tanto como parte/todo, quanto como quociente, e que também sejam capazes de realizar cálculos com frações, consigam compará-las e ordená-las, dentre outras habilidades. Durante toda a Educação Básica, em várias disciplinas, os estudantes serão novamente desafiados a resolverem questões que envolvem frações. Uma abordagem afrorreferenciada desse objeto tem potencial de valorizar a diversidade da cultura afro-brasileira.

Os mais antigos registros históricos sobre frações são os papiros matemáticos do Kemet. O principal deles é o papiro de Ahmes que apresenta 87 problemas relacionados ao cotidiano egípcio. Segundo Boyer (2002), este papiro é uma cópia de outro mais antigo. O escriba Ahmes a realizou em cerca de 1650 AEC. Carl Boyer (2002) enfatizou ser provável que o protótipo utilizado pelo escriba seja de 2000 
anos AEC. Por questões coloniais, infelizmente, o papiro se tornou mais conhecido como papiro de Rhind, devido ao antiquário Henry Rhind tê-lo adquirido em 1858. Atualmente, o papiro de Ahmes está no Museu Britânico, com exceção de alguns fragmentos que se encontram no Museu do Brooklyn. Em respeito ao escriba e comportando-nos de acordo com Powell e Temple (2006), chamamos a obra devidamente pelo nome do escriba que o transcreveu, Papiro de Ahmes. O documento foi escrito em hierático - a escrita cursiva para propósitos cotidianos (BOYER, 2002; EVES, 2004;) e tem cerca de 30 centímetros de largura e 5 metros de comprimento. Outra comprovação do uso de frações por antigos egípcios é apresentada por Georges Ifrah (1997). O historiador, mostrou que fragmentos do olho do deus Hórus eram relacionados à frações de uma medida de capacidade denominada héqat, no Kemet.

A metodologia utilizada para a elaboração do texto foi o estudo bibliográfico, sendo a decolonialidade a perspectiva teórica. Nos embasamos em Pinheiro (2021). De nossas leituras entendemos que a autora projeta a decolonialidade como (1ㅇ) movimento que insurge contra epistemicídios e pilhagens epistêmicas, e também como (2ㅇ) movimento de pessoas rumo a uma emancipação político-epistemológica em prol da dignidade humana. Epistemicídios, dentre outros fatores, estão relacionados aos silenciamentos sobre a ciência africana nas escolas. Pilhagens epistêmicas, no mesmo sentido, tem a ver com os roubos das ideias e de técnicas africanas que estudamos nas escolas como se fossem criações de europeus. Entendemos movimento emancipatório em prol da dignidade humana, a forma que a autora encontrou de impulsionar pesquisadores e profissionais da educação a elaborarem estratégias de educação antirracista e democrática.

Entendemos também que essa construção favorece a implementação das DCNERER no ensino de Matemática e coaduna com as intenções da Interculturalidade Crítica, de Catherine Walsh (2009). Para esta autora, interculturalidade crítica é uma ferramenta pedagógica que questiona continuamente os padrões de poder, as subalternizações e as interiorizações de pessoas (WALSH, 2009, p, 13). A seguir fazemos uma breve discussão sobre racismo científico e posteriormente abordaremos sobre a relação entre o mito de Hórus e Frações. 


\section{Influências do racismo no Ensino de Matemática}

Discussões sobre racismo no Brasil envolvem aspectos variados. Alguns autores o discutem pela ótica do racismo estrutural, outros o abordam pelo viés do racismo institucional. Também são frequentes estudos sobre desigualdades raciais, escravidão e Mito da Democracia Racial. Estas últimas abordagens se amalgamam aos aspectos específicos dos estudos teóricos sobre o racismo brasileiro.

O mito da raça dá sustentação ao racismo, comportamento humano ao qual não podemos indicar quando ou onde surgiu. Foram catalogadas algumas de suas formas autônomas em várias regiões do planeta e em diversos períodos históricos desde a Antiguidade (CAMARGO e BENITE, 2020; MUNANGA, 1998; WEDDERBURN, 2009). Nas antigas sociedades greco-romanas existiu escravidão e racismo. Historiadores indicam propostas racistas de Aristóteles e de Platão, por exemplo. O primeiro defendia a existência de raças que nasceram para servir e de raças que nasceram para dominar. O segundo filósofo sugeriu formas disfarçadas de praticar infanticídios em grupos socioculturais diferentes (WEDDERBURN, 2009). O racismo contra orientais foi difundido na cultura dos europeus e no século XIX adquiriu conotação científica, passando a favorecer a produção de teses biológicas sobre atraso, degeneração e desigualdades desses povos (SAID, 2007). Apesar de existirem registros racistas em culturas humanas desde a Antiguidade, como teoria, o fenômeno é uma doutrina relativamente recente.

Comportamentos racistas estão associados à xenofobia e regras socioculturais que interessam aos grupos dominantes. Esses grupos recorrem à ideia de raça, um dos mais eficazes e trágicos mitos da humanidade e o mais perigoso do nosso tempo, tendo força de exceder a própria realidade em si e ser impermeável ao pensamento racional (MONTAGU, 1945,). Desde que comprovou que seres humanos compartilham 99,9\% de material genético, a Genética abriu caminhos para a superação desta tragédia. Hoje podemos afirmar que não existem raças humanas e que nossas diferenças se dão por características fenotípicas. Entretanto, embasados nos $0,01 \%$ de nossas possíveis diferenças genéticas, ainda existem grupos de geneticistas que defendem a existência de raças biologicamente distintas. (WADE, 2017, p. 82)

O avanço do racismo está intimamente associado à expansão do 
capitalismo, aos interesses do cristianismo e do imperialismo global. Ele influencia as diversas desvalorizações de povos não-europeus. De acordo com Montagu (1945) os argumentos racistas são forjados a partir de três critérios: características físicas, capacidades mentais e alcance de altos níveis de civilização. O segundo critério está relacionado ao racismo científico. Machado e Loras (2017) destacaram posicionamentos racistas de filósofos europeus, dentre eles: (1) Hegel defendeu que povos nativos da América eram canibais, sem história e vocacionados à submissão; (2) Kant afirmou ser impossível um negro realizar um feito grandioso na ciência; (3) Hume afirmou não existir ciência entre os negros; (4) Weber alegou que uma gota de sangue negro desqualificaria uma pessoa e (5) Darwin declarou não existir africanos inteligentes. Esses exemplos são facetas da "história única". O mercador escravocrata John Lok ao relatar viagem ao continente africano declarou os negros como "animais que não tem casa" e "povo sem cabeça, com a boca e os olhos no peito" (LOK, 1561 APUD ADICHIE, 2019, p. 19). Essas ridículas construções históricas, reiteradamente, valorizaram as culturas e racionalidades dos europeus, normalizando a identidade europeia (SILVA, 2012).

O gobinismo, o nazismo e o darwinismo também são doutrinas racistas (MUNANGA, 1998, p. 43). Em conjunto com as elaborações apresentadas anteriormente, elas influenciaram teóricos racistas brasileiros como Silvio Romero, Gilberto Freyre, Nina Rodrigues e outros. Ressalta-se que esse racismo científico influencia tanto a cultura e a sociedade brasileiras, que tivemos no Brasil, uma Constituição Federal que estimulou a educação eugênica (BRASIL, 1934, Art. 138). Ademais, o racismo científico corroborou atrocidades humanas, além da escravidão. Sánchez Arteaga (2010) nos informa sobre exibições de pessoas em zoológicos, juntamente com animais, no início do século XX. Para o autor, não se encontra justificativa científica para esse fato. Ele ressaltou que a biologia humana e a antropologia física ortodoxa forneceram teorias que legitimaram essas exposições humanas em zoológicos. Noutro texto, o autor, voltando-se para a segunda metade do século XIX, afirma que o escravismo, o imperialismo, a violência simbólica e o discurso da biologia ortodoxa legitimaram violências e corroborarem ideologias que negavam a humanidade de pessoas (SÁNCHEZ ARTEAGA, 2007).

A ideologia do racismo científico impacta também nos apagamentos e 
silenciamentos das invenções de africanos e afrodiaspóricos para a ciência em geral. O fazer científico que desconsidera a história dos povos, que não analisa as relações socioculturais, imperialistas e capitalistas entre os povos e governos, e que não se atenta às relações de dominação, pode reforçar o racismo científico.

Existem tecnologias africanas nas áreas de agricultura, arquitetura, astronomia, biologia, cerâmica, engenharia, escrita, filosofia, física, química, marcenaria, matemática, medicina, mineralogia, navegação, olaria, pecuária, religião, têxteis, entre outras (CUNHA ET AL, 2005; MACHADO E LORAS, 2017). Alguns dos conhecimentos matemáticos dominados por africanos são: sistemas de numeração; simbologia; construção de pirâmides; invenção do "Triângulo de Pascal"; invenção de jogos e calendários (SILVA, 2018). O Teorema do Triângulo Retângulo, também conhecido por "Teorema de Pitágoras" é uma relação que era amplamente conhecida por povos mais antigos do que os gregos. Tatiana Roque relata que não existem indícios de que o teorema tenha sido demonstrado pelos pitagóricos. (ROQUE, 2012, p. 112). Para a autora, a convergência interessada das poucas fontes existentes, permitem duvidar da existência de um matemático de nome Pitágoras (lbidem, p. 103).

A "história única", no Ensino de Matemática, ao denominar a relação por "Teorema de Pitágoras", silencia as dúvidas sobre a existência desse matemático, ao mesmo tempo em que silencia outras histórias que afirmam que ele, provavelmente, tenha aprendido o teorema que leva o seu nome, durante o período que teria morado no Egito (DIOP APUD GERDES, 2011). A "história única" valoriza a Matemática grega, entretanto ao se comportar assim, esconde que a cultura de Kemet surgiu 2000 anos antes da civilização grega. Os papiros keméticos de Ahmes e de Moscou apresentam problemas de multiplicação; divisão; proporção; resolução de problemas semelhanças de triângulos; problemas de progressões aritmética e geométrica e volume do tronco de pirâmides, enquanto o papiro de Cairo apresenta 40 problemas, 9 deles, lidam com o Teorema do Triângulo Retângulo (EVES, 2004). A esta lista Théophile Obenga (1995) acrescenta que os egípcios também lidavam com cálculo da superfície da esfera; trigonometria e simetrias.

Ademais, existem evidências de que matemáticos da antiguidade como Apolônio, Arquimedes, Aristarco, Aristóteles, Diofanto, Eudoxo, Eratóstenes, 
Euclides, Hiparco, Platão, Ptolomeu e Tales de Mileto estudaram no Egito. Além dos notáveis matemáticos, também estudaram no antigo Egito, outras personalidades gregas como Sólon, Licurgo, Demócrito Anaximandro, Anaxágoras, Heródoto, Homero, Isócrates e muitos outros. Alguns deles, relataram sobre os seus estudos naquela região. (ASANTE, 2015, p. 08). Não é demasiado destacar que a cidade de Alexandria, considerada cidade grega no Egito, não era uma cidade nova. De acordo com Asante, os gregos simplesmente expandiram uma antiga cidade egípcia existente, chamada de Rhacôtis e mudaram seu nome. (ASANTE, 2015). Os silenciamentos sobre contribuições de povos marginalizados à matemática reforçam estereótipos elaborados por Hegel, Kant, Hume, Darwin e outros. A narrativa valoriza apenas a Matemática grega, escondendo que essa civilização foi "resultado do intercâmbio cultural de muitos povos, principalmente os africanos". (PINHEIRO, 2021).

\section{Interculturalidade crítica e Ensino de Matemática.}

Como visto, as narrativas hegemônicas de construção das ciências marginalizaram as técnicas matemáticas não europeias. Para romper com essa lógica racista é preciso reconhecer influências da cultura sobre o ensino. Desde o final da década de 1980, em várias partes do mundo, o ensino de Ciências tem dado atenção para as culturas em diferentes frentes de pesquisa. As primeiras propostas eram vinculadas a concepções multiculturalistas. Posteriormente, passou-se a considerar também a interculturalidade, abrindo espaço para diálogos e transformações como elementos estruturantes do ensino. (PINHEIRO e BAPTISTA, 2021, p. 39).

Pinheiro e Baptista (2021) defendem a promoção da justiça e emancipação no Ensino de Ciência. Ao buscarmos alternativas que subsidiam decolonizar o ensino de matemática, estamos prosseguindo por caminho semelhante ao desses autores. É necessário produzir narrativas inclusivas, éticas, que respeitam a vida e que favoreça a construção de uma nova sociedade (WALSH, 2009) 


\subsection{Frações na antiguidade africana.}

\section{a) Frações em escrita hieroglífica}

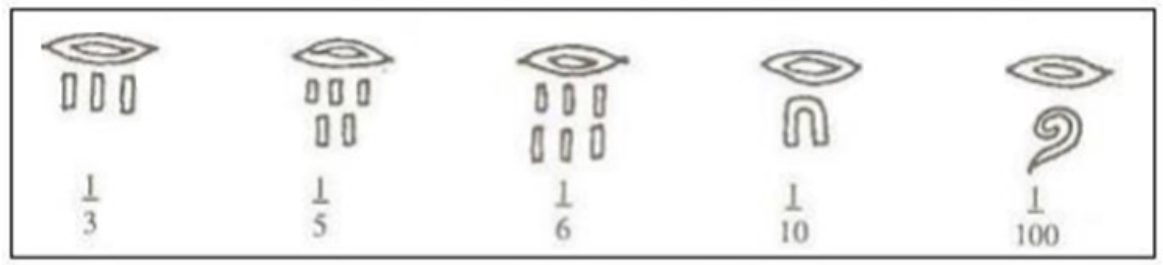

Figura 1. Frações na numeração hieroglífica egípcia. Fonte: IFRAH, 1997, Vol.1, p. 349.

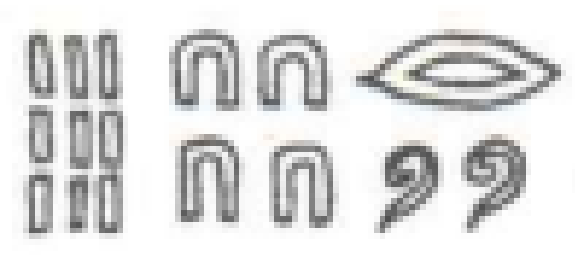

Figura 2. Fração 1/249 na numeração hieroglífica egípcia. Fonte: IFRAH, 1997, Vol.1, p. 349.

As figuras 1 e 2 acima são representações egípcias de frações, escritas em hiróglifo.



Quando o denominador tinha muitos algarismos e o sinal da boca não podia ficar sobre ele completamente, "escreviam o excedente na sequência" (fig. 2) Nesse sistema, havia representações específicas para as frações 1/2, 2/3 e 3/4 (lbidem, ibidem)

Informar os estudantes que africanos antigos usavam frações desconstrói narrativas hegemônicas de que na África não existia cultura e nem conhecimento. A ideia é motivadora para construção de jogos, tipo dominós, com diferentes, representações numéricas. Também é possível discutir com os estudantes sobre sistemas numéricos antigos, mostrando que os povos construíram diferentes técnicas em diferentes contextos culturais. Além de comprovar que a matemática é uma ciência que não está pronta e acabada.

\section{b) um mito sobre deuses egípcios e frações submúltiplos do héqat}

Iniciamos esta sessão com um resumo do mito egípcio que envolve os deuses 
Osíris, Hórus, Ísis e Seth.

De acordo com uma das versões da mitologia, os deuses do panteão egípcio viviam com os humanos na terra. As narrativas indicam que dois deles, Osíris e Ísis, eram irmãos gêmeos e se apaixonaram ainda no ventre materno (HIPERCULTURA, (2)). Osíris desposou Íris e se tornou o primeiro soberano do Egito, realizando um governo justo e bom. Entretanto, o deus Seth, irmão deles, movido pela inveja assassinou Osíris. Por meio de um ardil, Seth fez com que o irmão entrasse em um ataúde e juntamente com seus seguidores, aprisionaram Osíris e depois lançaram seu corpo no rio Nilo. Com a morte de Osíris, Seth tornou-se o governador do Egito. Esta terra, que antes era promissora, passou a viver um período ruim sob o comando do usurpador (HIPERCULTURA). A deusa Ísis conseguiu resgatar o corpo do companheiro com o intuito de ressuscitá-lo. Sabendo disso, para evitar que Ísis cumprisse o seu propósito, Seth localizou o corpo do irmão morto e o retalhou em várias partes, espalhando-as por lugares distintos do Egito. Ísis, com ajuda de Néftis, conseguiu juntar os pedaços do corpo do companheiro, com exceção do órgão genital, que foi substituído por um órgão de ouro (HIPERCULTURA). A ressuscitação de Osíris ficou a cargo do deus Anúbis, filho dele com Néftis.

Por meio de magia, Ísis engravidou do companheiro, gerando um filho que foi chamado de Hórus. Ela o criou alimentando o desejo de vingar-se. Quando se sentiu preparado, o deus Hórus desafiou o tio e desenvolveram uma demorada batalha. No conflito, Seth arrancou o olho esquerdo de Hórus e o dividiu em 6 partes, espalhando-as pelo Egito. Este, por sua vez, conseguiu castrar o tio na batalha. A assembleia dos deuses interveio na sangrenta guerra e decidiu a favor de Hórus, que assumiu o trono do Egito. A assembleia também determinou que Thot, outro deus, juntasse os fragmentos do olho de Hórus e Seth foi amaldiçoado a ser o senhor do mal. (IFRAH, 2017, p. 353)

O mito resumido acima se relaciona com a cultura matemática do Kemet. De acordo com Ifrah, o hèqat uma antiga medida de capacidade kemética, equivalente a aproximadamente 4,8 litros era usada para medir grãos e líquidos, como cerveja, por exemplo. Os submúltiplos do hèqat estão associados às seis partes em que o olho do deus Hórus (também chamado de deus falcão por ter corpo humano e cabeça dessa ave), foi dividido. De acordo com Ifrah, os 
submúltiplos mais usuais do hèqat eram 1/2, 1/4, 1/8, 1/16, 1/32 e 1/64 e cada parte do olho representava uma dessas frações. Na figura 3, à esquerda está ilustrado o olho de Hórus. À direita temos uma representação do olho associado a às frações do héqat.
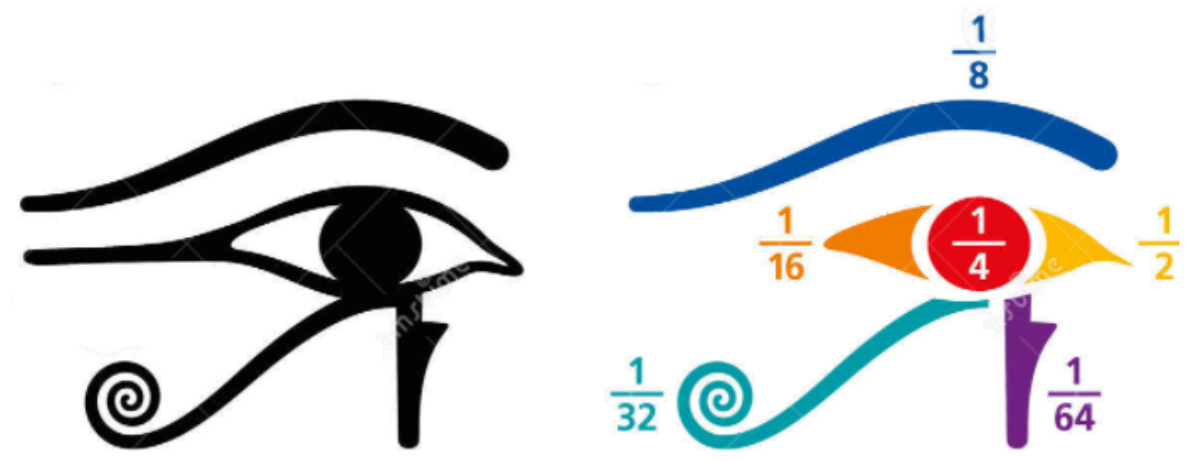

Figura 3. Olho de Hórus (à esquerd). A notação das frações do héqat para medidas de capacidade. Fonte: https://pt.dreamstime.com/ilustra\%C3\%A7\%C3\%A3o-stock-o-olhode-horus-fractions-valores-aritm\%C3\%A9ticos-colorido-image93811838

A leitura pode ser feita tanto da esquerda para direita quanto direita para a esquerda. Atribuía-se 1/2 à parte direita da córnea, 1/4 à íris, 1/8 à sobrancelha e 1/16 à parte esquerda da córnea

É possível relatar outros aspectos e versões do mito kemético buscando-o na internet ou em livros. Além das disciplinas que indicamos que poderão participar de uma atividade é possível discutir sobre medidas de capacidade, sobre alimentos e também sobre bebidas egípcias. Perguntas como: Se o olho fosse dividido em mais 4 partes, em que fração chegaria. Se adicionarmos as seis frações correspondentes aos submúltiplos do hèqat, a que resultado chegamos? Existe diferença de dificuldade na leitura da direita para esquerda e vice-versa?

\subsection{Notação atual de frações}

Boyer relata que a notação atual de frações, com numerador e denominador separados por uma barra, foi "usada regularmente" por Fibonacci, mas que esta notação já era conhecida por árabes (BOYER, 2002, p. 173). Existem textos matemáticos mulçumanos escritos em árabe, mas, de acordo com Gerdes não é possível afirmar que os autores foram árabes. Ele reproduziu um manuscrito do século 12, escrito em árabe, da direita para a esquerda, afirmando ser o mais antigo texto em que aparecem frações com a notação atual. Disse também que, 
provavelmente, o autor do texto tenha sido Abdallah Ibn al-Yasamin, um mulçumano negro que foi professor, matemático, jurista e poeta (GERDES, 2012, p. 95 -96). Segue abaixo a reprodução do referido manuscrito (fig. 4).

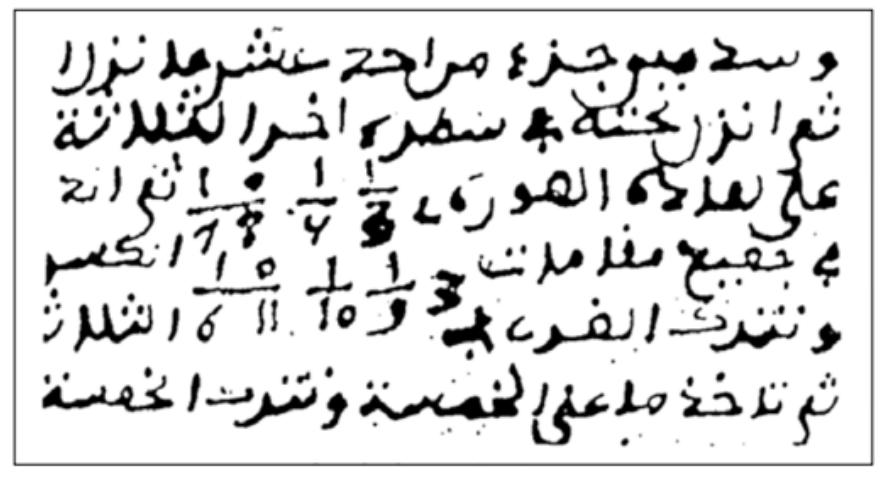

Figura 4. Parte de um manunscrito do Magreb (século XII) (GERDES, 2012)

O manuscrito revela que nós ainda utilizamos, corriqueiramente, invenções africanas na escola. Infelizmente, não somos informados disso.

\section{Considerações finais}

Esse texto teve objetivo de apresentar subsídios para elaboração de propostas de ensino afrorreferenciado de frações. São três possibilidades para diferentes níveis de ensino. A primeira delas (3.1 a) pode ser utilizada com estudantes que iniciam o estudo de frações, a terceira (3.2), em qualquer série posterior e a segunda (3.1 b) é mais adequada a turmas de jovens e adultos ou turma a partir do $6^{\circ}$ ano, tendo em vista que o mito apresenta trechos que tratam de morte e vingança. Aconselha-se, nesse caso, consultar as normas escolares e da Rede de Ensino. Esperamos que com a canção de Luciano Gomes e com o mito kemético consigamos incentivar propostas interculturais para o ensino de Matemática. Recomendamos assistir o documentário da BBC News (2017) que apresenta aspectos da Matemática egípcia, tratando, inclusive do olho de Hórus.

\section{Referências}

ADICHIE, Chimamanda Ngozi. O perigo de uma história única. Companhia das Letras, 2019.

ASANTE, Molefi Kete. Raça na Antiguidade: na verdade, provém da Africa. Capoeira-Humanidades e Letras, v. 1, n. 3, p. 105-113, 2015. Título original Race in Antiquity: truly out of Africa. Tradução de Fernando Lopes Tomé. 
BBC News. A história da matemática (The story of maths). Direção: Marcus Du Sautoy. Produção: Érik Soares: BBC News - Documentários, 2017. https://www.youtube.com/watch? v=Ztz6VXOkIPc.

BENITE, Anna M. C.; CAMARGO, M. J. R. e AMAURO, Nicéa Q. (Orgs). Trajetórias de descolonização da escola: o enfrentamento do racismo no ensino de ciências e tecnologias. Belo Horizonte: Nandyala, 2020.

BOYER, Carl B. História da Matemática. Título original: A History of Mathematics. Trad. Elza F. Gomide. São Paulo: Edgard Blücher, 2002. 4ª reimpressão.

BRASIL. Constituicão da República dos Estados Unidos do Brasil, 1934.

BRASIL. Lei $\mathbf{N}^{\circ} \mathbf{9 . 3 9 4}$ de 20 de dezembro de 1996. Estabelece as Diretrizes e Bases da Educação Nacional.

BRASIL. Orientações e Ações para a Educação das Relações Étnico-Raciais. MEC. SECAD. Brasilia, 2006.

CAMARGO, Marysson Jonas R.; BENITE, Anna Maria Canavarro. Cartografias do Racismo e Resistência. In: BENITE, Anna M C; CAMARGO, M J R e AMAURO, Nicéa $Q$ (Orgs). Trajetórias de descolonização da escola: o enfrentamento do racismo no ensino de ciências e tecnologias. Belo Horizonte: Nandyala, 2020.

CUNHA, Lázaro Raimundo dos Passos. Contribuição dos povos africanos para o conhecimento científico e tecnológico universal. Salvador: Secretaria Municipal de Educação e Cultura, 2005. http://www.acaoeducativa.org.br/fdh/wpcontent/uploads/2012/11/contribuicao-povos-africanos.pdf

D' AMBROSIO, Ubiratan. Etnomatemática - elo entre as tradições e a modernidade. Belo Horizonte: Autêntica, 2005. $2^{a}$ ed.

EVES, Howard. Introdução à história da matemática. Título original: An introduction to the history of mathematics. Trad. Hygino H. Domingues. São Paulo: UNICAMP, 2004.

GERDES, Paulus. Pitágoras africano: um estudo em cultura e educação matemática. Centro moçambicano de pesquisa Etnomatemática. Maputo, 2011

GERDES, Paulus. Incorporar ideias matemáticas provenientes da África na educação matemática no Brasil. QUIPU: Revista Latinoamericana de História de las Ciencias y la Tecnología. 2012. V.14, n.1, p. 93-108.

GIRALDO, Victor; MATOS, Diego; QUINTANEIRO, Wellerson. Entre epistemologias hegemônicas e sabedorias outras: a matemática na encruzilhada. Revista Latinoamericana de Etnomatemática, v. 13, n. 1, 2020. p. 49-66.

GOMES, Luciano. Faraó - Divindade do Egito. https://www.youtube.com/watch? $v=$ pdNHfnnNvV8 .

HIPERCULTURA. Deus Hórus: a incrível história do deus dos céus do Antigo Egito. https://www.hipercultura.com/horus-historia-do-deus-egipcio 
IFRAH, Georges. História Universal dos Algarismos. Título original: Histoire universalle des chiffres. Trad. Alberto Muñoz. Rio de Janeiro: Nova Fronteira, 1997.

MENDONÇA, Paulo Tarso de. Paulo Freire e a Educação Matemática. Vídeo. 1995. http://www.acervo.paulofreire.org:8080/jspui/handle/7891/1880

MACHADO, Carlos; LORAS, Alexandra. Gênios da humanidade: ciência, tecnologia e inovação africana e afrodescendente. São Paulo: DBA, 2017.

MONTAGU, MF Ashley. Man's most dangerous myth: The fallacy of race. Columbia University Press, 1945. $6^{\mathrm{a}}$ ed.

MUNANGA, Kabengele. Teorias Sobre o Racismo. In: HASENBALG [et al] Racismo: perspectivas para um estudo contextualizado da sociedade brasileira. Niterói: EDUFF, 1998.

OBENGA, Théophile. La géométrie égyptienne: contribution de l'Afrique antique à la mathématique mondiale. L'Harmattan, 1995.

PINHEIRO, Bárbara Carine S. História Preta das Coisas. São Paulo: Livraria da Física, 2021.

PINHEIRO, Bárbara Carine S; ROSA, Katemari (Orgs.) Descolonizando saberes: a Lei 10.639 no ensino de ciências. São Paulo: Livraria da Física, 2018.

PINHEIRO, Paulo César; BAPTISTA, Geilsa C. S Em Busca de referências culturais para a educação científica. In: BAPTISTA, Geilsa C. S.; PINHEIRO, Paulo César; FARIAS, Luiz Márcio S. Educação científica por meio da interculturalidade de saberes e práticas. Salvador: EDUFBA, 2021.

POWELL, Artur; TEMPLE, Oshon L. O papiro matemático de Ahmes e estudantes urbanos. In: RIBEIRO, José Pedro Machado; DOMITE, Maria do Carmo Santos; FERREIRA, Rogério. Etnomatemática: papel, valor e significado. Zouk, 2006.

SAID, Edward. Orientalismo: o oriente como invenção do ocidente. Tradução Rosaura Eichenberg. Título original: Orientalism - Western conceptions of the Orient. São Paulo: Companhia das Letras, 2007.

SÁNCHEZ ARTEAGA, Juan Manuel. La racionalidad delirante: el racismo científico en la segunda mitad del siglo XIX. Revista de la Asociación Española de Neuropsiquiatría, v. 27, n. 2, p. 111-126, 2007.

SÁNCHEZ ARTEAGA, Juan Manuel. La antropología física y los uzoológicos humanosil: exhibiciones de indígenas como práctica de popularización científica en el umbral del siglo XX. Asclepio, v. 62, n. 1, p. 269-292, 2010.

SILVA, Getúlio Rocha; FARIAS, Luiz Marcio S. Caminhos para uma descolonização epistemológica: contribuições para a descolonização da Didática da Matemática. In: BENITE, Anna Maria Canavarro [et al.] (Orgs). Trajetórias de descolonização da escola: o enfrentamento do racismo no ensino de ciências e tecnologias. Belo Horizonte: Nandyala, 2020. 
SILVA, Rosiléia Santana da; FARIAS, Luiz Marcio Santos. Descolonização Didática: uma proposta do Ensino de História para o ensino das diferentes ciências. In: BENITE, Anna Maria Canavarro [et al.] (Orgs). Trajetórias de descolonização da escola: o enfrentamento do racismo no ensino de ciências e tecnologias. Belo Horizonte: Nandyala, 2020.

SILVA, Tomaz Tadeu da (Org.); HALL, Stuart; WOODWARD, Kathryn. Identidade e diferença: a perspectiva dos estudos culturais. Petrópolis, RJ: vozes, 2009. $9^{\mathrm{a}} \mathrm{ed}$.

WEDDERBURN, Carlos Moore. Racismo e sociedade: novas bases epistemológicas para entender o racismo. Belo Horizonte: Mazza, 2007.

WADE, Perer. Raça e etnia na era da ciência genética. In:HITA, Maria Gabriela. Raça, racismo e genética em debates científicos e controvérsias sociais. EDUFBA, 2017. Págs. 81-101

WALSH, Catherine. Interculturalidad crítica y pedagogía de-colonial: apuestas (des) de el in-surgir, re-existir y re-vivir. UMSA Revista (entre palabras), v. 3, p. 30-31, 2009.

WEGNER, Robert. Dois geneticistas e a miscigenação. Octavio Domingues e Salvador de Toledo Piza no movimento eugenista brasileiro (1929-1933). Varia História, v. 33, p. 79-107, 2017. 